\title{
Correction to: Comparison of analgesic effect of oxycodone and morphine on patients with moderate and advanced cancer pain: a meta-analysis
}

Kai-Kai Guo', Cheng-Qi Deng ${ }^{2}$, Gui-Jun Lu ${ }^{1 *}$ and Guo-Li Zhao ${ }^{1}$

\section{Correction}

After publication of this article [1], the authors noted that the corresponding email address is incorrect. The correct correspondence address is luguijun301@163.com. The correct correspondence address can also be seen below.

\section{Author details}

'Department of Pain Management, The Center of Anaesthetized Operation, Chinese PLA General Hospital, No. 28 Fuxing Road, Beijing 100853, China. ${ }^{2}$ Department of Anesthesiology, First Affiliated Hospital of General Hospital of PLA, Beijing 100048, China.

Published online: 19 November 2018

\section{Reference}

1. Guo KK, Deng CQ, Lu GJ, Zhao GL. Comparison of analgesic effect of oxycodone and morphine on patients with moderate and advanced cancer pain: a meta-analysis. BMC Anesthesiol. 2018;18(1):132. https://doi.org/10. 1186/s12871-018-0583-8.

\footnotetext{
*Correspondence: luguijun301@163.com

${ }^{1}$ Department of Pain Management, The Center of Anaesthetized Operation,

Chinese PLA General Hospital, No. 28 Fuxing Road, Beijing 100853, China

Full list of author information is available at the end of the article
} 